\title{
REFLEXÕES SOBRE COLONIZAÇÃO E INTERAÇÃO CULTURAL NO BRASIL E NA AMÉRICA DO NORTE*
}

\author{
Lígia Bellini \\ Departamento de História Universidade Federal da Bahia
}

\begin{abstract}
RESUMO: Busca-se, no artigo, fazer uma reflexão sobre tópicos relevantes para um estudo do contato entre europeus e as populações indígenas no primeiro século da colonização do Brasil, à luz de trabalhos sobre processos similares que tiveram lugar na América do Norte. Discute-se, entre outros aspectos, a importância de se procurar recapturar as expectativas e opções existentes, e as escolhas feitas, num momento em que o desenlace dos processos que tiveram lugar nos primeiros tempos da colonização ainda não havia se definido. Enfatiza-se a natureza plurilateral do encontro, reconhecendo, no entanto, que não se trata de uma interação simétrica entre as partes envolvidas. Procura-se colocar a parte negligenciada pela historiografia tradicional, os índios, no centro da cena, e compreender as suas visões e a sua perspectiva em relação aos eventos do período.
\end{abstract}

PALAVRAS-CHAVE: Interação Cultural, Colonização, Brasil, América do Norte, Ação Indígena.

ABSTRACT: The article discusses the contact between Europeans and indigenous populations in the first century of the colonization of Brazil, taking as reference the work of ethnohistorians in North America. It adresses, among other aspects, the importance of attempting to recapture the options that existed and the choices that were made by the history's actors in a period in which the denouement of the encounter was not yet defined. It focuses upon the multi-lateral nature of the contact, although recognizing that it was not a symmetrical one. The Indian's role as historical agents is thrown into relief by seeking to understand their views and attitudes regarding the events of that period.

KEYWORDS: Cultural interaction, Colonization, Brazil, North America, Indigenous Agency.

* O presente artigo foi escrito com base em pesquisa patrocinada pelo Conselho Nacional de Desenvolvimento Científico e Tecnológico, CNPq.
Historians look backward, up the stream of time, but history's actors, in their own time, looked forward into the ill-charted flow of the future James Axtell 
Ao olharmos, do presente, para os inícios da colonização americana, a visão que se tende a ter está impregnada pelo conhecimento do desenlace dos processos que tiveram lugar em diferentes partes da América. A idéia da inevitabilidade da drástica redução das populações ameríndias pela guerra e doenças infecciosas, e da desagregação dos seus costumes é, em geral, um componente fundamental na compreensão que temos do fenômeno. Mas isto, evidentemente, não era assim para os seus protagonistas. No período inicial de formação das colônias, em que as relações entre conquistadores e nativos desenvolviam-se com grande dinamismo, esse desfecho não estava senão insinuado. Se quisermos compreender os modos como indivíduos e grupos sociais estiveram envolvidos nesse processo, é preciso desfocar nosso olhar sobre o que posteriormente ocorreu e tentar recapturar as expectativas e opções existentes naquele momento, as escolhas feitas, e os resultados imediatos, além dos resultados de longo curso, de suas ações (AXTELL, 1985, esp. p. 5; KUPPERMAN, 1980, esp. p. 12)1.

Um outro elemento que, durante muito tempo, caracterizou as abordagens historiográficas aos processos de colonização é a ausência de uma compreensão mais aprofundada das visões e atitudes dos nativos, enfim, da sua atuação como sujeitos históricos. Na formulação de James Axtell, a grande maioria dos historiadores os considerou como notas de pé de página na escrita da história americana. A propó-

\footnotetext{
${ }^{1}$ Ao investigarmos processos iniciais de contato, é preciso ter em mente que, muitas vezes, as cronologias gerais de cada colônia não são de muita utilidade. No caso brasileiro, por exemplo, contatos iniciais entre europeus e tribos Tupinambás e Tupiniquins se deram na Bahia nas primeiras décadas do século XVI, enquanto os começos da inter-relação entre portugueses e Tobajaras (Tupis) e Cariris (Gês) no Ceará datam dos inícios do século XVII. Uma bem documentada análise das especificidades da conquista em cada região brasileira encontra-se em HEMMING, 1978.
}

sito do Brasil, Manuela Carneiro da Cunha observa que sua história canônica é inaugurada pelos "descobridores", conferindo-se aos gentios uma entrada "de serviço". Ou, como nota James Ronda a respeito da empresa evangelizadora, "os historiadores tenderam a enxergar a história das missões como a luta entre a dinâmica cristandade européia e tradições indígenas ossificadas" (AXTELL, 1989, p. 223; CARNEIRO DA CUNHA, 1992, p. 9; RONDA, 1977, p. 67). Este quadro está associado a diferentes fatores, entre os quais o primeiro é o fato de que são da autoria de europeus os registros sobre os eventos, sendo, nas civilizações indígenas, ausentes a escrita e frágeis os testemunhos materiais deixados. Autores que discutiram esta questão em geral apontam também o fato de que a natureza das relações estabelecidas foi, em grande medida, determinada pela iniciativa e pelos objetivos dos europeus, e de que o encontro teve como conseqüência uma transformação muito mais radical das comunidades indígenas, não raro ao ponto de causar sua inteira destruição. Além disso, durante todo o período inicial de conquista, e mesmo após o estabelecimento das colônias em bases mais estáveis, o encontro ocorreu quase que exclusivamente nas Américas, e não na Europa, implicando que os nativos ficassem na posição de quem respondia, reagia, resistia à entrada de estranhos em seu mundo. Há que se considerar ainda o etnocentrismo da historiografia do chamado mundo ocidental. E há autores que propõem, a par dessas razões, outras mais específicas, como a de que as populações autóctones estariam tão integradas no meio ambiente que os cronistas ficaram propensos a vê-las mais como parte deste, compondo uma espécie de pano de fundo da conquista, do que como agentes históricos, transmitindo esta visão aos historiadores (JAENEN, 1976, p. 8).

Como observa Axtell, não é que as culturas européias na colonização não tenham sido predominantemente ofensivas, e as culturas ameríndias predominantemente defensivas, mas isto não significa que as 
últimas não possuíam iniciativa e não desenvolveram uma multiplicidade de modos de fazer face às novas condições. As respostas dos nativos foram determinantes fundamentais na constituição de todas as colônias européias na América (AXTELL, 1982, esp. p. 40; 1989, p. 223). Além disso, partir da constatação de que a documentação escrita disponível foi produzida pelos colonizadores e que, desta forma, expressa principalmente características e interesses desse grupo, não implica a impossibilidade de identificar, nela, formas de ação histórica dos índios² .

No presente artigo, busca-se fazer uma reflexão sobre tópicos relevantes para um estudo do contato entre europeus e as populações indígenas no primeiro século da colonização do Brasil, à luz de trabalhos sobre processos similares que tiveram lugar na América do Norte. Tais trabalhos foram publicados principalmente a partir da década de 1970 e, de diferentes modos, estão voltados para a superação dos problemas apontados acima, quais sejam, a centralidade do nosso conhecimento sobre os resultados posteriores do processo inicial de colonização na análise que dele fazemos, e o desequilíbrio na tentativa de compreender os "dois lados da equação cultural"”. De um modo geral, os estudiosos da colonização americana cujas obras são aqui discutidas

\footnotetext{
${ }^{2}$ No sentido de procurar construir quadros mais complexos da lógica do funcionamento das sociedades ameríndias nos começos da colonização, o historiador dispõe ainda da técnica denominada de "upstreaming" ou projeção etnográfica, quer dizer, a utilização dos resultados de estudos etnográficos de grupos indígenas nos séculos XIX e XX na interpretação de sociedades indígenas do passado. Essa perspectiva envolve uma série de problemas, entre os quais o principal está associado ao pressuposto de uma continuidade nos modos de vida nativos nos séculos posteriores à conquista, mas ainda assim tem demonstrado utilidade. Ver, a esse respeito, WHITE, 1991, p. xiv; e FAUSTO, 1992.

${ }^{3}$ Esta formulação encontra-se em SCHWARTZ, 1994, "Prefácio", p. xiii.
}

enfatizam a natureza plurilateral do encontro, reconhecendo, no entanto, que não se trata de uma interação simétrica entre as partes envolvidas. Tais estudiosos tomaram para si a tarefa de colocar a parte negligenciada pela historiografia tradicional, os índios, no centro da cena, e procurar compreender as suas visões sobre os eventos do período. Uma reflexão sobre os problemas e idéias postulados por esses autores se justifica por terem emergido num contexto particularmente fértil de rediscussão da participação dos vários agentes na constituição das sociedades coloniais na América do Norte e, apesar disso, se tratar de trabalhos grosso modo ausentes das bibliografias de estudos sobre o Brasil. Rediscussão semelhante tem também ocorrido na historiografia brasileira, embora, nesta, as pesquisas não parecem ter sido impulsionadas e influenciadas por um movimento indígena na mesma medida que na América do Norte, em que o movimento indígena americano, a partir dos anos 70, foi determinante no desenvolvimento do interesse de pesquisadores pelo tema. Isto fica evidente em vários títulos da bibliografia aqui analisada.

Ao menos em parte, as investigações discutidas neste artigo foram influenciadas por idéias desenvolvidas em trabalhos nas áreas de sociologia e antropologia. Para citar somente alguns exemplos, a dificuldade de abordar, nas ciências humanas, sociedades consideradas como predominantemente tradicionais da perspectiva da mudança foi observada por Clifford Geertz, no início dos anos 70: "A visão que temos das religiões asiáticas e africanas é singularmente estática. Se espera delas que prosperem ou entrem em declínio; mas não se espera que mudem" (GEERTZ, 1973, p. 170). E análises do processo pelo qual o contato entre diferentes universos culturais, cada um procurando pôr em prática suas próprias expectativas e concepções num novo contexto, resulta em mudança nas culturas originais, foram feitas por Anthony Giddens e Marshall Sahlins (GIDDENS, 1979 e 1984; SAHLINS, 1981 e 1990. Ver também WAGNER, 1975, esp. cap. 5). 
Num certo sentido, este é um estudo comparativo, já que, nele, procura-se analisar comparativamente fatos e processos ocorridos em diferentes partes da América. Entretanto, é importante notar que só se utiliza, aqui, documentação primária relativa ao Brasil, sendo os demais lugares abordados somente através de trabalhos historiográficos sobre os mesmos. Ficaram de fora, neste ensaio, obras sobre a América espanhola, porque estas, em geral, tratam de encontros coloniais envolvendo sociedades indígenas cujas diferenças em relação às encontradas no Brasil são muito maiores que as dos grupos autóctones da América do Norte (Ver, por exemplo, CLENDINNEN, 1996; e GREENBLATT, 1993 e 1996). A presença, em tais sociedades, de vida sedentária, agricultura intensiva, governos dinásticos e diferenciação acentuada entre grupos sociais, sistemas de cobrança de impostos, aparato religioso complexo e outros atributos levou inclusive certos estudiosos a postular e a investigar homologias entre esses sistemas culturais e os europeus (LOCKART, 1994, esp. p. 218-219).

Da mesma forma que em relação aos começos da colonização do Brasil, a documentação disponível para o estudo da América do Norte constitui-se centralmente de escritos de missionários. Como argumenta Axtell, o descobrimento da América "redirecionou a energia evangelizadora da Cristandade européia para o ocidente, pondo os nativos americanos em contato com a noção civilizada de conquista como conversão" (AXTELL, 1985, p. 329). Este e outros historiadores cujas investigações são aqui referidas não consideram a ação missionária simplesmente como uma tentativa de converter os nativos à fé cristã, ou de resguardá-los da escravização e da cobiça dos colonos em relação à terra. A evangelização é vista como um empreendimento cujo objetivo era o de transformar radicalmente os indígenas, requerendo que estes renunciassem a sua cultura e se tornassem semelhantes aos europeus em todos os aspectos da vida, em outras palavras, fossem plenamente incorporados ao mundo ocidental cristão.
A propósito do período formativo do Brasil como colônia portuguesa, concepção similar foi proposta por Luiz Felipe Baêta Neves, que demonstrou ser falaciosa a polarização entre, por um lado, a ênfase na "humanização" promovida pela Companhia de Jesus em terras brasileiras e, por outro, sua importância como parte integrante do sistema de dominação colonial portuguesa. Baêta Neves postulou que poder e saber compunham uma mesma estratégia da missão jesuítica (BAÊTA NEVES, 1978). Com seu método de reunir e instruir os nativos em aldeamentos sob sua guarda, onde procuravam promover a aculturação e assimilação dos índios, os padres da Companhia teriam servido aos interesses da Coroa portuguesa em promover a organização e o domínio da colônia. De acordo com esta perspectiva, os freqüentes conflitos entre jesuítas e colonos, em torno do problema da escravização dos índios ${ }^{4}$, devem, segundo Stuart Schwartz, ser vistos como o confronto entre duas diferentes técnicas para tornar os nativos úteis à economia colonial e, de modo mais amplo, promover sua "europeização". Os colonos seriam a favor do uso de coerção direta através da escravização. Os padres procurariam criar um campesinato indígena pela via da aculturação e destribalização (SCHWARTZ, 1985, p. 35-36).

\footnotetext{
${ }^{4}$ Ver, entre outras, a carta de Nóbrega a Simão Rodrigues (Bahia, 9 agosto 1549), in LEITE, 1956-68, vol. 1, p. 121-122; as cartas de Nóbrega a Tomé de Sousa e aos padres em Portugal (1559), in NÓBREGA, 1931, p. 206 e 190, respectivamente; e a carta de Leonardo Nunes (São Vicente, 8 agosto 1550), in Cartas Avulsas (15501568), 1988, p. 57. É preciso notar, no entanto, que os padres não eram contra a escravização dos índios considerada "justa", quer dizer, a escravização de comunidades nativas tidas como hostis (ver, por exemplo, a carta de Nóbrega a Miguel de Torres (Bahia, 8 maio 1558), in LEITE, 1956-68, vol. 2, p. 449), e que sua opinião a propósito desta questão vai se transformando com o passar do tempo. Este aspecto é discutido com mais detalhe adiante.
} 
A caracterização geral da evangelização como uma empresa destinada a revolucionar as culturas tradicionais ameríndias se aplica tanto ao esforço missionário feito principalmente pelos jesuítas, mas também por outras ordens religiosas, no Brasil e no Canadá, quanto às missões protestantes na Nova Inglaterra. O que há de comum entre processos envolvendo diferentes nações européias, e grupos com distintas afiliações religiosas e políticas, nos autoriza a admitir a existência de uma concepção de América partilhada pelos europeus, resultante, em parte, de um equipamento mental e intelectual comum não especificamente nacional, católico ou protestante, e em parte do impacto do Novo Mundo nos desenvolvimentos espirituais, intelectuais, políticos e econômicos na Europa, nos inícios da época moderna (JAENEN, 1976, p. 9-10). Às vezes é também surpreendente a similaridade entre comportamentos e atitudes dos ameríndios face ao contato em diferentes partes do continente, mas, quanto a esse aspecto, é preciso ter em mente que, se povos indígenas distintos tiveram hábitos e reações semelhantes, muitas vezes eles diferiam radicalmente uns dos outros. Isto obviamente também se aplica aos colonizadores europeus (JAENEN, 1974, p. 264-265; AXTELL, 1985, p. X-xi). Em verdade, os encontros coloniais nunca ocorreram entre genéricos "índios" e "europeus", mas entre segmentos particulares desses grupos (determinadas tribos ou aldeias indígenas, por um lado, e facções dos colonizadores brancos, por outro), envolvendo sub-grupos que diferiam entre si em idade, gênero, status social, parentesco e no modo como percebiam o momento histórico que estavam vivendo (Ver AXTELL, 1992, p. 100).

No caso brasileiro, a documentação contendo informações sobre crenças e atitudes dos índios nos começos da colonização compõe-se de escritos de indivíduos de diferentes nacionalidades, com diferentes afiliações religiosas, e cujo envolvimento com os nativos deveu-se a razões de ordens diversas. Ao lado da correspondência e das crônicas dos padres da
Companhia de Jesus, há os relatos dos capuchinhos franceses Claude d'Abbeville e Yves d'Évreux e do calvinista Jean de Léry, do colono português Gabriel Soares de Souza, do historiógrafo francês André Thévet, e do artilheiro alemão Hans Staden, entre outros. Embora o material produzido por esse conjunto heterogêneo de cronistas deva ser lido com particular cuidado crítico, para não considerar certas afirmações fora de contexto, há uma razoável coerência nas informações oferecidas. Vale lembrar ainda que eram Tupis, em sua maior parte, as diferentes tribos que ocupavam a costa brasileira quando da chegada dos europeus, e com quem estes estabeleceram um contato mais estreito. Essas tribos possuíam língua e costumes muito semelhantes, o que sugere que sua separação deve ter se dado numa época não muito distante do momento da conquista (HEMMING, 1978, p. 24).

Várias das fontes acima mencionadas apresentam vívidas descrições das atitudes dos nativos frente à chegada dos europeus. Entretanto, é a correspondência jesuítica, por cobrir os diversos passos do contato e seus desdobramentos durante um longo período, que melhor expressa a dinâmica da interação cultural, a reformulação de princípios e expectativas, as acomodações e mudanças.

Quando se compara o desenrolar do trabalho missionário dos jesuítas no Brasil e na Nova França, uma questão que emerge é a de em que medida os experimentos inacianos na América Latina, durante o século XVI, eram conhecidos pelos jesuítas que atuaram na América do Norte, no século XVII, e influenciaram sua ação. Há registros de que as reservas indígenas introduzidas em 1637 no Canadá tiveram como modelo as reducciones do México e do Paraguai (JAENEN, 1976, p. 177). Mas o que surpreende não é o empréstimo da idéia de que a segregação em aldeamentos seria a melhor forma de promover a conversão dos nativos, e sim o fato de que muitas vezes se observa missionários na Nova França tendo concepções acerca dos índios, e pondo em prática táticas cotidianas para atraí-los 
para a fé cristã e modificar seu comportamento muito semelhantes às relatadas com detalhe na correspondência dos padres do Brasil quase um século antes, e muitas delas incorretas ou mal sucedidas. Um exemplo disso é que jesuítas recém-chegados no Canadá, nas primeiras décadas do século XVII, acreditavam que não havia, nas sociedades ameríndias que encontraram, uma dimensão religiosa, e que as mentes dos nativos eram tabulas rasas nas quais a fé católica poderia ser facilmente inscrita (JAENEN, 1976, p. 41-43). Esta, como se sabe, foi também a concepção inicial dos padres da Companhia, ao chegarem ao Brasil ${ }^{5}$. Como ocorreu no Brasil, os padres no Canadá criticavam agressivamente e expunham ao ridículo público crenças e práticas dos nativos e seus xamãs, sem perceber que este era um comportamento considerado abominável nas etiquetas dos diferentes povos indígenas (AXTELL, 1985, p. 94; NÓBREGA, 1955, p. 56; LEITE, 1956-68, vol. 3, p. 206; MAESTRI, 1994, p. 128).

Por outro lado, os inacianos que atuaram na América do Norte muitas vezes reproduziram características positivas do trabalho no Brasil, México e Paraguai, como a tenacidade e habilidade para enfrentar os obstáculos encontrados em sua missão nas colônias. Uma dificuldade com que os jesuítas tiveram que lidar em terras brasileiras foi o isolamento em relação aos demais padres e a Europa, sugerido em diversas passagens da sua correspondência ${ }^{6}$. Mas esta

\footnotetext{
${ }^{5}$ Recém-chegado ao Brasil, Nóbrega relatava a Simão Rodrigues: "Hé gente que nenhum conhecimento tem de Deus, nem idolos..." (Bahia, 10? Abril 1549); "Cá poucas letras bastam, porque é tudo papel branco e não há mais que escrever à vontade..." (Bahia, 9 Agosto 1549). NÓBREGA, 1955, p. 21 e 54, respectivamente. Essa concepção parece ter permanecido até 1551, quando Nóbrega escreveu: "Os Gentios, que parece que punham sua bemaventurança em matar os contrarios e comer carne humana e ter muitas mulheres, se vão muito emendando, e todo o nosso trabalho consiste em os apartar disto; porque todo o demais é facil, pois não
}

foi apenas uma entre muitas, incluindo problemas relativos a acomodação, alimentação, e conflitos com os colonos e com membros do clero secular, fartamente documentados nas cartas. A maior parte dos estudiosos da colonização menciona e ilustra de diferentes formas a adequação da Companhia de Jesus, quanto a sua estrutura, princípios e formação dos seus membros, para pôr em prática o projeto evangelizador nas Américas. A ordem foi organizada segundo um modelo militar, e seus membros treinados para perseguir infatigavelmente o objetivo de combater o protestantismo e o paganismo. A uniformidade doutrinal e a sofisticada formação em lógica, línguas e retórica constituem elementos comuns aos inacianos que atuaram nas diferentes partes do continente americano.

Uma outra característica comum, que teve grande relevância na orientação do projeto de catequização, e em particular no desenrolar de alguns processos aqui analisados, foi a relativa flexibilidade com que os padres, em certos momentos do contato, trataram uma série de aspectos dos modos de vida ameríndios (AXTELL, 1985, esp. caps. 4-6; 1992, cap. 6; JAENEN, 1976, cap. II). Pouco depois da fundação da Companhia de Jesus, Inácio de Loyola orientou seus discípulos a adotar uma postura de tolerância seletiva quanto às culturas não familiares aos euro-

têm ídolos...". Carta aos padres em Portugal (Pernambuco, 1551). NÓBREGA, 1931, p. 114. Ver tambem carta de Nóbrega a D. João III: “...em cousa nenhuma crem, e estão papel branco pera nelles escrever hà vontade..." (Olinda, 14 Setembro 1551). NÓBREGA, 1955, p. 99-100.

${ }^{6}$ Ver as cartas de Diogo Jácome aos padres e irmãos em Coimbra (São Vicente, Junho 1551); e Francisco Pires aos padres em Coimbra (Bahia, 7 agosto 1552), in LEITE, 1956-68, vol. 1, p. 241, 246 e 247; e 392, respectivamente; de Brás Lourenço aos padres em Coimbra (Espírito Santo, 26 março 1554), in LEITE, 1956-68, vol. 2, p. 39; e de Nóbrega a Miguel de Torres e padres em Portugal (Bahia, 5 Julho 1559), NÓBREGA, 1955, p. 294. 
peus. Aceitando certos aspectos dos costumes dos diferentes povos, os inacianos poderiam conquistar sua simpatia e melhor fazer avançar a obra missionária (LOYOLA, 1903-1911, vol. 1, p. 179-180). Nas várias partes do mundo em que atuaram, os padres da Companhia fizeram adaptações nas práticas católicas, traduziram a fé cristã em termos familiares aos povos com quem conviveram e procuraram estabelecer relações entre as crenças e valores éticos destes e os princípios cristãos. Nas missões na China, os jesuítas usavam as vestimentas locais e celebravam missa em chinês, além de aceitar que indivíduos convertidos à fé cristã participassem dos rituais familiares em honra dos mortos e venerassem o imperador. $\mathrm{Na}$ Índia, toleravam a prática de rituais relativos às castas. Essa postura de relativismo também foi sustentada no trabalho com os Hurons, no Canadá ${ }^{7}$.

No Brasil, os padres, apesar de sua austeridade moral e religiosa como típicos representantes da Reforma Católica, utilizavam canções e instrumentos musicais indígenas na missa e outros rituais católicos; permitiam que os índios convertidos participassem nus desses rituais, e que também deles participassem pessoas que não haviam sido batizadas; e utilizavam, em suas pregações, gestos imitados aos chefés e pajés (LEITE, 1956-68, vol. 2, p. 351-352; Cartas Avulsas, 1988, p. 424; NÓBREGA, 1931, p. 141-142). Esses experimentos, como também ocorreu em relação ao trabalho missionário dos jesuítas

\footnotetext{
${ }^{7}$ Peter A. Dorsey considera que a prática jesuítica de acomodação em relação aos costumes dos povos junto aos quais os inacianos atuaram deveu-se, em grande medida, a sua admiração com respeito às línguas nativas e à crença numa autoria divina destas. Com base na idéia da existência de uma gramática universal, os padres teriam enxergado as marcas de Deus nas línguas e, por extensão, nas culturas dos povos que encontraram. DORSEY, 1998. Sobre os antecedentes da adaptabilidade cultural da Companhia de Jesus e exemplos de flexibilidade na atuação da ordem, ver JAENEN, 1976, p. 50-51; ALDEN, 1996, p. 67-71.
}

em outras partes do mundo, não eram de forma alguma unanimemente considerados aceitáveis pelo clero católico como um todo. Isto nos é sugerido pela reação do primeiro bispo do Brasil, D. Pero Fernandes Sardinha. Ao chegar à colônia em 1552, quando os jesuítas vinham desenvolvendo seu trabalho missionário havia três anos, o bispo imediatamente manifestou sua desaprovação a respeito de vários aspectos dos métodos jesuíticos de educação religiosa, incluindo os mencionados acima. A disputa entre ele e os padres gerou diversas cartas de ambos os lados, numa das quais Fernandes recomendou ao Provincial em Portugal, Padre Simão Rodrigues, que enviasse ao Brasil missionários mais velhos e melhor instruídos em matéria teológica (LEITE, 1956-68, vol. 1, p. 364 565; JAENEN, 1976, p. 50-51).

A atitude de relativismo cultural dos jesuítas no Brasil é também evidenciada em seus esforços para adaptar o trabalho missionário aos padrões de casamento ameríndios. Escrevendo de Piratininga em 1554, Anchieta explica a Inácio de Loyola a necessidade de não considerar impedimentos para o casamento relativos à consangüinidade, no sentido de tornar possível ministrar este sacramento aos índios. $\mathrm{O}$ padre argumenta que era comum entre os nativos estabelecer uniões com parentes, inclusive primos em primeiro grau, concluindo que, se os índios fossem obrigados a seguir as regras da Igreja Católica quanto a este e a outros aspectos, não havia dúvida de que não aceitariam se converter (LEITE, 1956-68, vol. 2, p. 114). O pedido de Anchieta, de um afrouxamento nas regras relativas à consangüinidade para uniões cristãs entre os índios, foi endossado por outros padres, como Diego Mirón e Nóbrega (LEITE, 195668, vol. 2, p. 126; NÓBREGA, 1955, p. 205-206).

No Brasil, como é discutido com mais detalhe adiante, à medida em que as respostas dos índios foram frustrando as expectativas iniciais dos missionários, estes passaram a adotar uma postura mais severa, lançando mão de métodos de coerção mais rígidos 
para alcançar seus objetivos. É importante observar ainda que, em nenhum momento, os jesuítas se dispuseram a aceitar práticas de fundamental importância no universo social e cultural dos brasis, como a poligamia, o canibalismo e a guerra. A reversão, nas missões no Brasil, de uma postura de maior flexibilidade para uma maior rigidez no que tange à aceitação de costumes tradicionais indígenas, parece ter se dado no sentido oposto ao ocorrido na Nova França. Nesta última, os padres teriam iniciado o trabalho catequético com uma atitude de relativa inflexibilidade, acreditando que as tribos deviam adotar costumes "civilizados" como uma preparação para a fé, para depois diminuírem suas exigências em relação à supressão de hábitos nativos. Exemplo disso é a instituição, a partir de 1640, de missões nômades, em paralelo às missões permanentemente estabelecidas em determinados locais (AXTELL, 1985, p. 59-62 e 110-111).

Um traço que parece ter caracterizado a atuação dos inacianos na América do Norte é que, diferentemente de outras ordens religiosas que lá realizaram trabalho missionário, os jesuítas não adotaram uma política de batismo em massa dos nativos (AXTELL, 1985, p. 122). Em terras brasileiras, também em relação a este aspecto observa-se uma transformação nos princípios e modo de agir dos padres. Nos primeiros anos do trabalho de catequização (até 1552), há indicações de uma maior cautela, por parte dos missionários, no que diz respeito ao batismo dos indígenas. Estes só eram considerados preparados para receber o sacramento após um período de instrução quanto aos preceitos cristãos, e a existência de evidências de que haviam de fato se convertido e de que permaneceriam fiéis à fé (Ver, por exemplo, NÓBREGA, 1955, p. 116; LEITE, 1956-68, vol. 1, p. 252 e 254). Relatos sobre batismos em massa passam a ocorrer no período da instituição dos primeiros aldeamentos, em que percebe-se um endurecimento das estratégias dos inacianos. Este é também o período em que o governador Men de Sá promoveu uma série de campanhas devastadoras contra os Tupinambás da Bahia, o que contou com a aprovação dos padres, que viam nelas uma forma de aumentar a população dos aldeamentos com as tribos vencidas (LEITE, 1956-68, vol. 3, p. 388-389 e 430; VASCONCELLOS, 1663, p. 175; ANCHIETA, 1958, Livro II, primeira parte).

As fontes sobre o período inicial da chegada dos europeus nas Américas indicam que os indígenas de modo algum aceitaram passivamente o projeto de conquista, conversão e transformação radical dos seus hábitos. Além dos vários exemplos disso mencionados neste ensaio, com referência a diferentes povos americanos, é interessante notar que muitas vezes, nas mitologias indígenas brasileiras, a própria desigualdade tecnológica em relação aos brancos é representada como uma escolha dos índios. Rezam os mitos de diferentes grupos que, no momento em que lhes foi dada a opção entre a espingarda e a espada de ferro, por um lado, e o arco e a espada de madeira, por outro, os nativos preferiram o equipamento tradicional (ABBEVILLE, 1922, fol. 69v-70r; CARNEIRO DA CUNHA, 1992, p. 18-19). Mesmo a posterior aceitação da conversão e dos princípios preconizados pelo projeto "civilizador" deve ser vista positivamente, como uma escolha num conjunto de alternativas possíveis, feita por grupos cuja cultura e sociedade, nos moldes tradicionais, já estavam em extinção, sob o impacto das guerras, das enfermidades, e da adoção de hábitos dos brancos que contribuíram para sua desagregação, como o consumo de bebidas alcoólicas. A manutenção dos modos de vida e crenças do período imediatamente anterior à chegada dos europeus já não era, pois, naquele momento, uma opção real. Foi assim com os índios aldeados, nas últimas décadas do século XVI, em diversas partes do leste do Brasil, e também com os habitantes das praying towns na Nova Inglaterra e das réserves no Canadá e na região dos Grandes Lagos (SALISBURY, 1974, p. 35-36; WHITE, 1991, p. 48; AXTELL, 1985, p. 332). 
Em estudo sobre as relações entre franceses e índios Algonquians na região dos Grandes Lagos nos EUA, nos séculos XVII e XVIII, Richard White procurou dar resposta à questão de que desdobramentos teria tido o fato de que era impossível, para os primeiros, ao menos durante um certo período de tempo, simplesmente impor suas regras aos índios, de quem dependiam como aliados, vizinhos, e parceiros nas trocas. Na formulação de White, teria se desenvolvido um processo de acomodação mútua, resultando na constituição de um universo cultural intermediário ("middle ground"), onde os dois grupos podiam interagir. Nesse universo intermediário as partes envolvidas ajustariam suas diferenças através do que ele chama de uma série de mal-entendidos. A princípio, cada parte procuraria seguir, na nova situação, convenções a seu ver consideradas normais, sendo tais convenções inexistentes no outro universo cultural, ou incompatíveis com ele. Esse processo estaria fundamentado no falso pressuposto, inicialmente vigente em ambos os lados, da viabilidade de uma homologia entre as categorias das ordens culturais em contato ${ }^{8}$. Entretanto, o aspecto central da invenção do "middle ground" consistiria num expediente utilizado a partir do reconhecimento das dissimilaridades pelos sujeitos envolvidos no contato, isto é, sua disposição de justificar suas próprias ações em termos do que consideravam ser as premissas culturais da outra parte. Dessas interpretações falsas e mal-entendidos teriam surgido novos sistemas de significado e troca, compartilhados pelos diferentes grupos no universo inter-

\footnotetext{
${ }^{8}$ Mecanismo semelhante é pressuposto no estudo de James Lockhart sobre as relações entre as culturas espanhola e Nahua no México. No entanto, Lockhart propõe que isto teria ocorrido por tratar-se de culturas similares sob vários aspectos, o que teria tornado possível que cada lado assumisse que conceitos análogos na outra sociedade eram essencialmente idênticos aos seus próprios. LOCKART, 1994.
}

mediário. Acomodação, segundo White, não é aculturação sob um novo nome. Na acepção usualmente aceita, aculturação refere-se a processos nos quais um grupo se torna mais semelhante a outro pelo empréstimo de certos elementos culturais. Para White, não é que os indígenas tenham se tornado afrancesados, ou os franceses tenham ficado mais parecidos com os nativos, mas que os dois mundos se diluíram nas margens e até certo ponto fundiram-se.

A criação do universo cultural intermediário supõe um processo de invenção pelos grupos envolvidos, tendo como primeiro estágio o momento em que cada um deles procura assimilar o outro em suas próprias categorias conceituais. White observa que o domínio da escrita pelos europeus conferiu a essa fase do encontro uma durabilidade que, de outra forma, não teria. Porque os franceses registraram por escrito suas impressões iniciais, esse conhecimento se difundiu para regiões muito distantes das do contato. Tal conhecimento deixou de ser posto em cheque pela vivência com os ameríndios. Muito depois de ter deixado de ser relevante para as ações daqueles que viviam entre os nativos, a idéia do homem selvagem, dotado de virtude e ferocidade naturais, persistiu entre os intelectuais e governantes na França. Esses "índios imaginários" foram os que inspiraram pensadores como Rousseau. Por esta razão, White considera uma série de escritos de europeus sobre a América e os índios de pouca utilidade para uma melhor compreensão do fenômeno da colonização. Ainda, segundo ele, pouca utilidade teria pensar o encontro centralmente segundo a noção de imperialismo. Para White, trata-se de um imperialismo que se enfraquece na sua periferia (WHITE, 1991, esp. "Introduction" e p. 50-53).

As proposições de White remetem ao problema epistemológico que está na base das diferenças entre abordagens historiográficas a situações de contato cultural. Para alguns estudiosos, os relatos de europeus que viveram na América ou a visitaram nos in- 
formam centralmente sobre as concepcões e os objetivos dos seus autores e do seu ambiente cultural, e não sobre as sociedades observadas. De acordo com esta opinião, as narrativas de viajantes, missionários e outros cronistas se aproximariam das de indivíduos que escreveram sobre a América na Europa, sem ter tido uma vivência direta em terras americanas, e cujos escritos, segundo White, de pouco serviriam para analisar os processos de colonização. Para outros autores, é possível, a partir das crônicas, correspondência e relatos de viagem dos europeus que estiveram na América, compreender as culturas nativas e as ações dos seus membros, ainda que de forma imperfeita e limitada. Esta opção não implica desconsiderar a questão da representação ou, em outras palavras, a influência, no ato de observar, de concepções muitas vezes implicitamente assumidas pelo observador a respeito de si mesmo e do outro, e de aspectos que constituem suas diferentes identidades. Por exemplo, vários estudos têm demonstrado como descrições do Brasil estavam impregnadas de elementos do equipamento mental dos europeus. Laura de Mello e Souza e Ronald Raminelli examinaram a demonização dos nativos brasileiros (MELLO E SOUZA, 1986 e 1993; RAMINELLI, 1996). Raminelli também investigou como os europeus projetaram concepções misóginas nas imagens das mulheres nativas por eles produzidas (RAMINELLI, 1996, p. 84-108). Fleischmann e outros identificaram elementos míticos e convenções nos modos como o canibalismo foi descrito na literatura de viagem sobre o Brasil (FLEISCHMANN, 1990-91). E Stephen Greenblatt explorou elementos do imaginário medieval que influenciaram as práticas representacionais dos europeus com relação à América (GREENBLATT, 1996). Entretanto, há evidências de que a experiência do contato provocou reajustes nas concepções e expectativas carregadas da Europa, da mesma forma que causou mudanças no olhar dos demais grupos envolvidos no encontro colonial. É essa constante reformu- lação das expectativas e visões de cada uma das partes que constitui a dinâmica dos fenômenos de contato inter-cultural.

Esse modo de compreender a interação entre diferentes culturas é postulado nas análises de Marshall Sahlins. Sahlins propõe que "o grande desafio a uma antropologia histórica não é simplesmente saber de que modo os eventos são ordenados pela cultura, mas como, ao longo do processo, a cultura é reordenada". Para este autor, "esquemas culturais são ordenados historicamente porque, em maior ou menor grau, os significados são reavaliados quando realizados na prática...; por um lado, as pessoas organizam seus projetos e dão sentido aos objetos partindo das compreensões preexistentes da ordem cultural... Por outro lado, entretanto, como as circunstâncias contingentes da ação não se conformam necessariamente aos significados que lhes são atribuídos por grupos específicos, ... os homens criativamente repensam seus esquemas convencionais. É nesses termos que a cultura é alterada historicamente na ação" (Respectivamente, SAHLINS, 1981, p. 8; e 1990, p. 7).

Um dos casos mais ilustrativos de dinâmica da interação cultural no primeiro século da colonização do Brasil envolve a associação, feita pelos índios Tupis, com quem os jesuítas tiveram um contato mais estreito, entre os padres e as figuras consideradas como dotadas de poderes mágicos nas comunidades nativas. O pajé, como se sabe, era uma espécie de feiticeiro cujas funções consistiam em proteger o grupo contra ameaças externas, comunicar-se com os espíritos, presidir as cerimonias religiosas, controlar fenômenos naturais, curar doenças e fazer profecias. Era também o guardião da tradição, papel que dividia com o chefe, a liderança política da aldeia. Pajés com poderes especiais tornavam-se "caraíbas", profetas que viajavam de aldeia em aldeia divulgando uma mensagem messiânica sobre a "terra sem mal", descrita como um lugar edênico onde reinava a abundância, no qual a sobrevivência seria obtida sem es- 
forço, a enxada iria sozinha para o campo e as flechas perseguiriam a caça sem intervenção humana. Era, além disso, fonte de imortalidade, onde os mais velhos se tornariam jovens outra vez. Os profetas também prometiam que todos os inimigos seriam derrotados, e que os índios teriam muitos prisioneiros para sacrificar em rituais antropofágicos. De acordo com Nóbrega, o "feiticeiro" (isto é, o caraíba) “....lhes diz que não curem de trabalhar, não vão à roça, que o mantimento por si crescerá, e que nunca lhes faltará que comer, e que por si virá a casa; e que as aguilhadas irão a cavar, e as frechas irão ao mato por caça para o seu senhor, e que hão-de matar muitos dos seus contrários e cativarão muitos para os seus comeres. E promete-lhes larga vida, e que as velhas se hão-de tornar moças, e as filhas que as dêem a quem quizerem..." (NÓBREGA, 1955, p. 63). O poder da profecia era infundido no pregador por meio de um instrumento mágico chamado "maracá", feito com o fruto seco da cabaceira. Uma característica importante desses rituais religiosos tupis era o transe. As cerimônias incluíam cantos, e a ingestão de beberagens e tabaco. Os poderes atribuídos aos caraíbas faziam com que as comunidades por onde passavam os tratassem com grande respeito e submissão, manifestados por gestos de cortesia como cânticos, danças, a limpeza do caminho que iriam percorrer, e a oferta de presentes. Há relatos fazendo referência ao fato de que eram seguidos por grupos de pessoas ao se aproximarem das aldeias, e de que estas rogavam que eles as protegessem contra doenças e outros males (Ver, por exemplo, NÓBREGA, 1955, p. 62-63) 9 .

Como os caraíbas, os missionários da Companhia de Jesus andavam de aldeia em aldeia, muitas vezes solitários, comunicavam-se com um "espírito", pre-

\footnotetext{
${ }^{9}$ Uma caracterização geral dos atributos do pajé e do caraíba encontra-se em MÉTRAUX, 1979, cap.VII.
}

gavam a respeito da vida após a morte, além de possuir, aos olhos dos nativos, estranhos poderes e objetos. A associação, feita pelos índios, entre jesuítas e xamãs, se evidencia em passagens da correspondência em que os padres relatam ter recebido tratamento semelhante ao usualmente dado aos feiticeiros. António Pires, escrevendo aos padres e irmãos de Coimbra em 1552, relata que, após ter aparentemente "convencido" um feiticeiro numa discussão, recebeu a oferta de grande quantidade de milho de mais de uma aldeia, explicando que o "seu intento hé que lhe demos muyta vida e saude e mantimento sem trabalho como os seus feiticeiros lhe prometem". Menção a presentes oferecidos pelos índios aos inacianos, em troca de ensinamentos cristãos, é também feita por Leonardo Nunes, em carta a Nóbrega. Nunes faz referência ainda a ocasiões em que os índios seguiam os padres, abrindo seu caminho e os tratando com deferência especial. E Anchieta observa que os índios atribuíam, a ele e outros padres, o poder de restituir a saúde, por terem conhecimento de Deus e o pregarem (LEITE, 1956-68, vol.1, p. 335 e 339-340; e vol. 2, p.307, respectivamente).

Mas essa homologia não se deveu simplesmente ao fato de os índios não terem compreendido as diferenças entre os códigos culturais em jogo. No seu intento de negar os poderes sobrenaturais dos xamãs indígenas e dos espíritos por eles conjurados, e atribuir tais poderes ao Deus cristão, os jesuítas em muito contribuíram para acentuar a imbricação entre aspectos dos dois sistemas religiosos. Visitando aldeias dos Tamoios em Iperoig, Anchieta falava "en voz alta por sus casas como es su costumbre" que lá estava para "enseñarles las cosas de Dios para que él les diesse abundancia de mantenimentos, salud y victoria de sus enemigos, y otras cosas semejantes..." (LEITE, 195668 , vol. 4, p.126). Como mencionou-se anteriormente, os padres imitavam gestos dos pajés nas pregações. Nóbrega e Vicente Rodrigues relatam episódios em que os missionários procuraram substituir os feiticei- 
ros na cura de doentes, afirmando que somente Deus e Jesus Cristo poderiam salvá-los da morte (NÓBREGA, 1955, p. 72-73; LEITE, 1956-68, vol.1, p. 306). Os padres aquiesciam mesmo aos pedidos dos nativos de que eles "impusessem a mão" sobre os doentes, para que estes viessem a se curar (NÓBREGA, 1955, p. 73). O resultado inicial dessas práticas parece ter sido menos o que desejavam os inacianos - isto é, a anulação das crenças nativas tradicionais e a adoção da fé cristã pelos índios - do que a transformação, por estes, dos padres em xamãs e do Deus cristão num espírito nativo. De acordo com o caráter inclusivo e flexível das religiões indígenas, o que permitia a adoção, ao mesmo tempo, de uma variedade de crenças e práticas, os inacianos e seu Deus podiam ser facilmente inseridos na ordem religiosa pré-existente.

O processo teve desdobramentos posteriores, quando enfermidades começaram a vitimar as populações com quem os jesuítas tinham maior proximidade. A suspeita de que, como podiam os feiticeiros que desejassem causar mal às aldeias, os missionários estariam propositalmente provocando a doença e a morte passou a concorrer com as expectativas positivas que os índios tiveram inicialmente em relação aos padres. Entretanto, desde os começos do contato, se em geral grande parte dos nativos parece ter-se mostrado predisposta a considerar a presença dos jesuítas como benéfica, há diversas indicações de que este não foi o caso dos próprios xamãs, que sentiramse ameaçados por sua concorrência no ato de curar e de mediar o contato entre o sobrenatural e a vida diária. Alguns meses após sua chegada ao Brasil, Nóbrega observava que os "feiticeiros" "são os maiores contrários que cá temos, e fazem crer algumas vezes aos doentes, que nós lhes metemos no corpo facas, tesoiras e coisas semelhantes, e que com isto os matamos"; e, noutra carta, que os pajés diziam que o batismo cristão levaria os doentes a morrer mais depressa (NÓBREGA, 1955, p. 64 e 72-73, respectivamente; ver ainda LEITE, 1956-68, vol.1, p. 255).
Segundo os missionários, os pajés afirmavam que o ensinamento mesmo da doutrina cristã aos índios lhes trazia a morte (LEITE, 1956-68, vol.1, p. 256). Essa interpretação era, de fato, em parte correta, apesar de identificar erroneamente os mecanismos pelos quais as enfermidades eram transmitidas. Diante da evidência da disseminação drástica das doenças letais aos gentios, muitas vezes prevaleceu a imagem nociva da presença e da religião dos missionários, levando os índios, como relata Francisco Pires em 1551, "por persuasão dos feiticeiros, a fugirem dos padres, dizendo que lhes botavam a morte..." (Cartas Avulsas, 1988, p.155).

Um aspecto desse processo merece aqui ser ressaltado, qual seja, a existência, no interior das comunidades indígenas, de divergências quanto aos modos como seus membros percebiam e se posicionavam face ao encontro com os europeus. Os relatos acima evidenciam uma certa tensão entre pajés e os demais membros das aldeias indígenas, no tocante à aceitação da presença e das prédicas dos inacianos. Outras passagens da correspondência sugerem que a conversão ao Cristianismo de certos indivíduos numa aldeia podia causar conflitos entre estes e os demais índios. Tais conflitos podiam dever-se desde ao fato de os conversos adotarem novos padrões de moralidade e hábito, provocando rupturas na ordem sócio-cultural antes vigente, até ao favorecimento destes, em detrimento dos não convertidos, pelas autoridades civis e religiosas portuguesas. Em carta aos padres e irmãos de Coimbra, de 1551, António Pires relata que, entre os Tupinambás da Bahia, "Los christianos... son tan nuestros que contra sus naturales hermanos pelearam por nós defender, y están tan subjetos que no tienen cuenta con padres ni parientes... Grande es la embidia que los gentiles tienen a estos... porque ven quán favorecidos son del governador y de otras principales personas..." (LEITE, 1956-68, vol.1, p. 253-254).

Se havia diferenças radicais entre concepções sobre o sagrado e as maneiras de lidar com ele, é 
importante notar aqui que o hibridismo religioso cuja constituição vai sendo sugerida em passagens da correspondência jesuítica se deveu também à existência de certos pressupostos partilhados por cristãos e ameríndios em matéria de fé. Os dois sistemas religiosos incluíam a crença numa vida após a morte, assim como a idéia de uma dicotomia entre alma e corpo $^{10}$. Ambos costumavam explicar fatos da vida, e particularmente ocorrências extraordinárias, em termos da atuação de forças sobrenaturais. Os jesuítas no Brasil, ao tempo em que rejeitavam a idéia dos índios de que os males que os atingiam eram causados pela introdução, entre eles, do catolicismo, parecem ter por vezes acreditado que as doenças eram o resultado do descontentamento de Deus eram relação ao modos de vida nativos ${ }^{11}$. Processo semelhante também ocorreu com os jesuítas no Canadá (JAENEN, 1976, p. 103). Entre os missionários protestantes na América do Norte, em determinados casos tal modo de interpretar chegou ao extremo de considerar as epidemias que dizimaram as populações ameríndias como obra divina para facilitar a colonização, pela aniquilação dos nativos (KUPPERMAN, 1980, p. 3132). Passagens da correspondência jesuítica no Brasil sugerem também que os padres atribuíram muitas das desditas dos colonos portugueses à desaprovação divina em relação aos seus atos pecaminosos (Ver, por exemplo, NÓBREGA, 1955, p. 328ss.). A diferença residia no fato de que os missionários não reivindicavam poderes divinos para si, enquanto os índios acreditavam que alguns entre eles eram capazes de manipular forças sobrenaturais.

Além desta e outras diferenças já mencionadas, como a bipolaridade entre o caráter inclusivo e flexí-

\footnotetext{
${ }^{10}$ Sobre os Tupinambás, ver MÉTRAUX, 1979, p. 110-112.

${ }^{11}$ Ver cartas de Francisco Pires (1551). Cartas Avulsas, 1988, p.155; e Leonardo do Vale (1563). LEITE, 1956-68, vol. 4, p. 9.
}

vel das religiões indígenas e o exclusivismo do credo católico, observa-se a ausência de um impulso missionário nas religiões indígenas. Deste modo, os nativos não procuravam persuadir europeus a deixar de lado suas próprias crenças e adotar as tupis. Da mesma forma, a idéia de uma religião única para todos os povos devia parecer estranha aos olhos de indivíduos para quem a afiliação religiosa estava associada à circunstância do nascimento ou pertencimento a determinada tribo, e não a uma adoção voluntária da fé e o correspondente recebimento dos sacramentos.

Um outro exemplo nos dá indicações de que as respostas dos gentios à atividade missionária não podem ser facilmente reduzidas à mera aceitação ou rejeição da fé cristã: o movimento político-religioso denominado de "santidade". O termo foi originalmente usado pelos europeus para designar as manifestações religiosas tupis tendo como centro a crença mítica na "terra sem mal", prometida pelos caraíbas ${ }^{12}$. De meados do século XVI em diante, a santidade adquiriu cada vez mais as características de um movimento de resistência aos brancos, ocasionando migrações em massa para o interior, rebeliões e assaltos contra os portugueses. Seus seguidores acreditavam que, lutando contra os brancos e os vencendo, trariam o paraíso terrestre previsto pelos caraíbas. O culto messiânico tornou-se sincrético, assimilando vários elementos do Catolicismo. Seus ídolos, feitos de cabaça ou pedra, eram designados como "santos". A hierarquia da seita, assim como parte de seus símbolos, foram construídas com base na doutrina e organização da

\footnotetext{
${ }^{12}$ Ronaldo Vainfas apresenta uma caracterização das santidades tupis ainda não impregnadas de elementos cristãos, com base em descrições de Nóbrega (1549), André Thévet (1555-6), Hans Staden (1557) e Jean de Léry (1557-8). VAINFAS, 1995, p. 5062. A maior parte das informações mencionadas aqui foi retirada de seu estudo.
} 
Igreja Católica. Havia "papas”, "bispos”, "missionários", "igrejas", figuras cristãs como Maria, objetos como a cruz e o rosário, e rituais de batismo.

Os líderes do movimento eram índios que viveram com os portugueses, nas aldeias jesuíticas ou como escravos. A eles juntavam-se residentes das aldeias indígenas. Eventualmente, escravos africanos também participavam nos assaltos contra fazendas e vilas dos portugueses. Os seguidores das santidades atacavam plantações e engenhos, e algumas vezes impediram os jesuítas de dar continuidade ao trabalho missionário. Seus líderes instigavam a resistência ao domínio português através de mecanismos culturais e políticos que incluíam diversos elementos da religião dos opressores.

Movimentos religiosos como as santidades tupis emergiram em várias partes das Américas, muitos deles possuindo uma série de características similares. Eram em geral de natureza sincrética, misturando aspectos teológicos cristãos e indígenas, e organizavam-se em torno de um profeta indígena ou outro tipo de figura carismática. Denominados, pelos antropólogos, de "religiões de revitalização" ("revitalization religions"), esses movimentos são interpretados como uma tentativa, feita pelos membros de certas sociedades, de construir uma cultura mais satisfatória e adequada a determinada situação histórica. Constituem sem dúvida uma importante resposta positiva dos ameríndios contra a cristianização (WALLACE, 1956; HUNTER, 1971; RONDA, 1977, p. 79-80).

Para explicar o fenômeno da santidade no Brasil, Ronaldo Vainfas sugere que os índios filtraram e rearranjaram, "à moda tupi", o que haviam aprendido com os jesuítas. Desta forma, o hibridismo cultural que caracterizou as santidades teria sido produzido, em grande medida, nos aldeamentos da Companhia de Jesus (VAINFAS, 1995, esp. p.117).

A correspondência jesuítica e as obras de outros missionários como Évreux e Abbeville documentam fartamente os problemas semânticos que a evangeli- zação envolvia. É bem conhecido que os padres procuraram aprender as línguas nativas para se comunicar com os indígenas. Os inacianos utilizavam, de fato, a "língua geral", uma forma simplificada de tupi. Mesmo assim, em muitos casos, os padres tinham que fazer uso de tradutores quando pregavam e confessavam (Ver, por exemplo, NÓBREGA, 1955, p. 55, 87, 130-131; e LEITE, 1956-68, vol.1, p. 252) ${ }^{13}$. Muitos nunca conseguiriam aprender os idiomas indígenas. Quando, na medida das possibilidades, a barreira do domínio da língua era superada, persistia a dificuldade fundamental da adaptação de conceitos religiosos e filosóficos europeus ao universo cultural dos nativos, uma tarefa em relação à qual, no mais das vezes, se podia dar apenas soluções bastante insatisfatórias. Exemplo disso é como expressar, nas línguas tupis, idéias como a de pecado, culpa, céu, inferno (BOSI, 1992, p. 64-93). Nóbrega registrou, em sua correspondência, que as línguas nativas "Têm mui poucos vocábulos para lhes poder bem declarar a nossa fé, mas contudo damos-lha a entender o melhor que podemos e algumas coisas lhes declaramos por rodeios". E exemplificou, noutra passagem, os tipos de transposição conceitual utilizados: "Esta gentilidade a nenhuma coisa adora, nem conhecem a Deus, somente aos trovões chamam Tupana, que é como quem diz coisa divina. E assim, nós não temos outro vocábulo mais conveniente para os trazer ao conhecimento de Deus, que chamar-lhe Pai Tupana" (NÓBREGA, 1955, p. 66 e 62, respectivamente). Diversas passagens dos relatos de Évreux e Abbeville sobre as missões dos capuchinhos no norte do Brasil indicam igualmente a analogia entre o Deus cristão e

\footnotetext{
13 Uma discussão do papel dos intérpretes como intermediários culturais e elementos fundamentais na determinação da forma das relações entre os colonizadores ingleses e grupos indígenas no nordeste dos EUA encontra-se em HAGEDORN, 1997
} 
Tupã, assim como entre o demônio cristão e maus espíritos tupis (ÉVREUX, 1864, p. 269-270; 272-277; 280-283; ABBEVILLE, 1922, fol. 108r-108v).

Cedo os padres jesuítas observaram que determinadas formas de ritual agradavam em especial o gentio, e procuraram se utilizar disso no seu intento de ganhar prosélitos. António Blázquez expressa sua percepção da importância da música como elemento do rito religioso, para os índios: "em extremo são affeiçoados à musica e cantares, e en tanto que os feiticeiros, que entre elles chamão santos, usão desta manha quando lhes querem apanhar alguma cousa". E Nóbrega observa que os cantos "pelo mesmo toom dos Indios e com seus instromentos" "muyto atrahião os corações" destes (LEITE, 1956-68, vol.2, p. 351; NÓBREGA, 1955, p. 134). O padre Juan de Azpilcueta Navarro, tido como particularmente hábil na comunicação com os nativos, relata, entre outras coisas, que lhes ensinava o Padre Nosso "en modo de sus cantares para que más presto aprendessem y gustasen..." (LEITE, 1956-68, vol.1, p. 180; ver também NÓBREGA, 1955, p. 41). Certas passagens da correspondência jesuítica indicam que rituais como missas solenes e procissões, com os participantes devidamente paramentados e nos quais fossem entoados cantos acompanhados de instrumentos musicais, exerciam grande atração sobre os brasis. Como observa Blázquez, os novos rituais introduzidos pelos brancos podiam incorporar-se ao conjunto dos ritos praticados antes da sua chegada, ou mesmo servir para substituí-los: "Entonces sus bailes y beberes eran por honrar la fiesta de aquel contrario, cuja carne avían de comer, agora todo se muda en gloria y alabança del Señor" (LEITE, 1956-68, vol.4, p. 77-78).

A adesão, em geral entusiástica, dos gentios a esses rituais muitas vezes serviu de evidência, para os padres, de que eles haviam se convertido. Mas aqui, como observa Neil Salisbury a propósito da pretensa conversão dos nativos ao credo puritano na Nova Inglaterra, há indicações de que, para eles, o meio, muito mais do que o conteúdo, era a mensagem (SALISBURY, 1974, p. 51). Os índios respondiam afirmativamente às novas formas verbais e gestuais introduzidas pelos missionários sem ter compreendido o significado das pregações e preces a elas associadas. Em certos casos, é possível que os novos rituais tenham sido investidos, pelos nativos, de significados tradicionais. Esses mecanismos podem servir de explicação para o que os missionários caracterizavam como inconstância quanto ao cumprimento das normas cristãs. Após um período inicial de grande otimismo dos padres, em que os brasis pareciam aceitar com entusiasmo a evangelização, estes voltavam aos antigos hábitos. Logo os jesuítas se deram conta da dificuldade de eliminar aspectos constitutivos das sociedades tupis como o canibalismo ritual, a poligamia e a guerra. Em relato sobre a missão de Piratininga, datado de dezembro de 1556, Anchieta observa que “... não sòmente os grandes, homens e mulheres, não dão fruto não se querendo aplicar à fé e à doutrina cristã, mas ainda os mesmos muchachos que quasi criamos a nossos peitos com o leite da doutrina cristã, depois de serem já bem instruídos, seguem a seus pais primeiro em habitação e depois nos costumes..." (ANCHIETA, 1933, p. 92. Ver ainda LEITE, 195668, vol. 2, p. 207; e SOARES DE SOUSA, 1938, p. 47). Uma passagem do Dialogo sobre a conversão do gentio de Nóbrega expressa, melhor do que qualquer outra, a percepção da inconstância dos índios e das razões desta: “...com um anzol que lhes dê os converterei a todos, e com outros os tornarei a desconverter..." (NÓBREGA, 1954, p. 75).

Com o passar do tempo, os escritos jesuíticos sugerem uma crescente impaciência, que vai aos poucos substituindo o ardor missionário e o otimismo iniciais. Em carta datada de 1563, quando já estava vivendo no Brasil havia mais ou menos dez anos, Anchieta propunha: “... porque para este gênero de gente não há melhor pregação do que espada e vara de ferro" (ANCHIETA, 1933, p. 186). A frustração 
dos padres no que diz respeito aos resultados incertos do trabalho missionário levou a que alguns deles expressassem a idéia de que somente uma dominação mais radical de certos grupos indígenas, em outras palavras, sua escravização, garantiria sua submissão aos códigos morais e religiosos europeus. Em 1555, menos de dois anos após ter chegado ao Brasil, Anchieta escrevia a Inácio de Loyola sobre a conversão dos índios em São Vicente: "Não se pode... esperar nem conseguir nada em toda esta terra na conversão dos gentios, sem virem para cá muitos cristãos, que conformando-se a si e a suas vidas com a vontade de Deus, sujeitem os Índios ao jugo da escravidão e os obriguem a acolher-se à bandeira de Cristo" (LEITE, 1956-68, vol. 2, p. 207). Nóbrega, em certos momentos, endossou esta opinião, propondo que era preciso fazer o gentio "sobjeito e metido no jugo da obediencia dos christãos... porque hé ele de qualidade que domado se escreverá em seus entendimentos e vontades muyto bem a fé de Christo..." (Carta a Tomé de Souza (Bahia, 5 julho 1559), in LEITE, 1956-68, vol. 3, p. 72). Os missionários, que quando da sua chegada haviam tão veementemente se oposto à escravização dos nativos praticada pelos colonos, começaram a perceber que suas prédicas tinham melhor efeito em audiências cativas.

Também constituem exemplos da reação dos nativos americanos ao projeto de cristianização os questionamentos e respostas elaborados pelos índios face às proposições dos missionários e ao comportamento dos colonizadores em geral. Registros feitos por pregadores protestantes ingleses e jesuítas na América do Norte apontam formulações argutas, feitas pelos ameríndios, a propósito do fato de que o comportamento dos europeus nas atividades econômicas era muitas vezes contraditório em relação aos princípios cristãos, sobre o problema da morte, e sobre as idéias de pecado, culpa e castigo (AXTELL, 1985, p. 232-234; RONDA, 1977, passim; DORSEY, 1998, p. 402-403). No que tange às opiniões e questionamentos propostos pelo brasis, é importante observar inicialmente que a documentação de maior interesse não é a produzida pelos inacianos, e sim os relatos dos missionários franceses, que contêm o registro de uma série de debates entre eles e os índios, e de discursos destes últimos. Ao que tudo indica, os cronistas franceses procuraram, mais que os portugueses, compreender as visões de mundo e o entendimento que tinham os índios sobre o encontro. Isto se expressa em seu empenho em traduzir e registrar os discursos indígenas, o que contribui para que os escritos dos capuchinhos transmitam melhor as opiniões dos nativos. Mormente tais relatos exigirem cuidadosa leitura crítica, sendo evidente a influência das categorias de pensamento e objetivos dos cronistas na observação e compreensão das idéias e atitudes dos seus interlocutores nativos, eles são fontes de grande utilidade para uma exploração deste assunto.

As crônicas de Évreux sobre seus encontros com líderes indígenas no norte do Brasil sugerem o interesse com que estes discutiam, com os padres, aspectos da doutrina cristã, política, diplomacia e outros assuntos, muitas vezes propondo questões da maior relevância ${ }^{14}$. A propósito do significado da crucificação de Cristo, o chefe e feiticeiro Tupinambá Pacamont perguntou como era possível Deus morrer (ÉVREUX, 1864, p. 333). Em sua conversa com os missionários, este chefe expressou sua percepção da ritualística envolvida na constituição da imagem do governante e líder religioso, observando que havia refreado durante certo tempo seu desejo de visitá-los para manter a dignidade de chefe, de quem se espera que não demonstre excessiva ansiedade e disponibilidade. Buscando estabelecer uma relação de cumplicidade com os padres, por ele considerados como seus pares enquanto lideranças, observou que "nosso poder

\footnotetext{
${ }^{14}$ Os encontros são relatados em ÉVREUX, 1864, p. 325-364.
} 
sobre o povo é mantido pela gravidade que demonstramos em nossos gestos e oratória" (ÉVREUX, 1864, p. 327). Trechos dos relatos indicam ainda uma acurada compreensão, pelos índios, das diferenças sociais, políticas e tecnológicas entre eles e os europeus, e da situação de desvantagem em que se encontravam naquele momento, ao mesmo tempo em que expressam sua perplexidade diante de tais diferenças. Diz o chefe Iacoupen a Évreux : “...os franceses possuem riquezas em abundância, são valorosos, inventaram navios com que cruzam os mares, canhões... são bem vestidos e bem nutridos, temidos e respeitados. Nós, ao contrário, permanecemos vagabundos errantes, sem machados, foices, facas e outras ferramentas... Duas crianças nascem no mesmo momento, uma francesa e outra Tupinambá, ambas frágeis e delicadas. No entanto, uma terá todas essas comodidades e a outra viverá pobremente... me pergunto por que vocês franceses têm conhecimento de Deus e nós não..." (ÉVREUX, 1864, p. 352-353). Certas passagens da História da Missão dos Padres Capuchinhos, de Claude d'Abbeville, sugerem que os lideres Tupinambás do Maranhão, à altura em que Abbeville a escreveu, compreendiam claramente que a adoção do Cristianismo e a aliança com os franceses implicava a renúncia a aspectos centrais das culturas indígenas (ABBEVILLE, 1922, fol. 70v-71r).

É evidente, nas crônicas, o interesse dos franceses em apresentar argumentos a favor da conveniência da aliança e proteção por eles oferecidas aos índios. Entretanto, por outro lado, é preciso considerar que muitos dos Tupinambás que se aliaram aos franceses no Maranhão eram descendentes imediatos de tribos que haviam fugido dos portugueses em Pernambuco, e guardavam uma memória do contato anterior com os brancos. Percebe-se, nesse contexto, o empenho dos índios em colocar-se sob o governo francês, uma alternativa possível, quiçá a melhor, diante da inevitabilidade do domínio europeu. Pouco tempo depois, em 1616, seriam obrigados a procurar a proteção dos jesuítas portugueses, recém-chegados na região após a expulsão dos colonizadores franceses ${ }^{15}$.

Alianças entre nativos e europeus tiveram papel fundamental no desenrolar do processo inicial de contato e conquista, em terras brasileiras. Se esse processo compreende uma diversidade de situações históricas particulares, com acontecimentos e agentes específicos, os múltiplos episódios têm em comum o fato de que envolviam parcerias, muitas vezes com fins bélicos, entre brancos e índios. Os europeus logo aprenderam a utilizar a seu favor as rivalidades entre grupos indígenas. Na formulação de Frei Vicente do Salvador, este "foi sempre o modo mais facil das guerras que os portuguezes fizeram no Brasil" (SALVADOR, 1931, p. 117). Da mesma forma, os nativos perceberam, ainda que de uma perspectiva própria, os conflitos entre as nações metropolitanas, e se utilizaram deles. Mas aqui é necessário ter em mente as diferenças quanto a motivação, táticas e estratégias, tratamento dos prisioneiros, enfim, a concepção mesma de guerra. As guerras indígenas parecem ter tido como razão principal antigas vendettas, motivos inteiramente distintos das políticas estatais e objetivos econômicos que regiam os embates entre as potências européias na América. Após a chegada dos europeus, os conflitos entre índios passaram a envolver fatores como o uso de armas antes desconhecidas, as tensões e desorientação decorrentes do choque cultural, doenças e deslocamentos territoriais devidos à invasão, e o próprio estímulo dos colonizadores, no intento de obter escravos ou submeter grupos que ofereciam resistência ao projeto colonial. Além disso, franceses e portugueses passaram a arregimentar grandes números de guerreiros oriundos de diferen-

${ }^{15}$ A propósito da primeira colonização do Maranhão, ver HEMMING, 1978, cap. 10. Para as informações aqui mencionadas, ver esp. p. 212. 
tes tribos, contribuindo para descaracterizar os mecanismos tradicionais da guerra.

Nesse contexto, os nativos que não foram escravizados, ou morreram por doença ou nas guerras, procuraram formas de sobreviver nas novas condições, como por exemplo integrando-se aos aldeamentos missionários ou colocando-se sob governo europeu, ou ainda fugindo para zonas não ocupadas. Muitos se empenharam em tirar proveito das possibilidades de aliança com os brancos para conseguir derrotar um inimigo tradicional. Exemplo disso é a disposição dos Tamoios, durante o conhecido conflito envolvendo grupos indígenas inimigos aliados aos portugueses e franceses, de negociar com os portugueses quando estes romperam com seus parceiros Tupiniquins. Anchieta registrou que a principal razão que levou os Tamoios a desejar a paz "no fué el myedo que tuviessen a los christianos, a los quales siempre llevaron de vencida haziéndoles muchos daños, ni necessidad que tuviessen de sus cosas, porque los franceses, que tratan con ellos, se las dan en tanta abundancia assý ropas como herramientas, arcabuzes y espadas, ....mas el desseo grande que tienen de guerrear con sus enemigos los Tupis que hasta agora fueron nuestros amigos y poco ha se alevantaron contra nosotros..." (LEITE, 1956-68, vol. 4, p. 126-127). $\mathrm{O}$ conflito entre portugueses e Potiguares, estes últi-

\section{Bibliografia}

ABBEVILle, Claude d'. História da Missão dos Padres Capuchinhos na Ilha do Maranhão. Reproducção Fac-Simile com Prefácio de Capistrano de Abreu. Paris, Édouard Champion, 1922

ALDEN, Dauril. The Making of an Enterprise: The Society of Jesus in Portugal, Its Empire, and Beyond, 1540-1750. Stanford, Stanford University Press, 1996.

ANCHIETA, José de. Cartas, Informações, Fragmentos Históricos e Sermões (1554-94). Rio de Janeiro, Civilização Brasileira, 1933. mos parceiros dos franceses, na região ao norte de Pernambuco, motivou os Tobajaras, tradicionais inimigos dos Potiguares, a se aliarem aos lusos. A aliança, no entanto, foi rompida pelo chefe Tobajara Pirajiba quando da ameaça de escravização de sua tribo por uma expedição portuguesa em busca de cativos. Neste caso, diante do que constituiu, na visão dos chefe, uma traição por parte dos portugueses, este não relutou em se associar aos antigos inimigos Potiguares para atacá-los (SALVADOR, 1931, p. 220221). No Maranhão, conforme observou-se anteriormente, tudo indica que os Tupinambás aliaram-se aos franceses para se proteger contra a penetração colonial portuguesa.

De muitas formas, assim como ocorreu em outras partes da América, as populações indígenas no Brasil contribuíram para moldar as feições da colônia em formação. Compreendendo a nova situação em termos dos seus próprios princípios e expectativas, provocando mudanças nas estratégias econômicas e sociais dos colonizadores, construindo mecanismos de adequação ao momento histórico que estavam vivendo, os índios brasileiros, mesmo nas radicalmente adversas condições impostas pelos europeus, demonstraram que suas culturas eram sistemas dinâmicos, com capacidade de adaptar-se e de modificar as demais culturas com que interagiram.

De Gestis Mendi de Saa. Original acompanhado da tradução vernácula pelo Pe. Armando Cardoso. Rio de Janeiro, Arquivo Nacional, 1958.

AXTELL, James. "Some Thoughts on the Ethnohistory of Missions". Ethnohistory 29, 1982, pp.35-41.

.The Invasion Within: The Contest of Cultures in Colonial North America. New York e Oxford, Oxford University Press, 1985.

"Colonial America Without the Indians". In 
AXTELL, James. After Columbus: Essays in the Ethnohistory of Colonial North America. New York e Oxford, Oxford University Press, 1989, pp.222-243.

Beyond 1492: Encounters in Colonial North America. New York e Oxford, Oxford University Press, 1992, pp. 97-121.

BAÊTA NEVES, Luiz Felipe. O Combate dos Soldados de Cristo na Terra dos Papagaios: Colonialismo e Repressão Cultural. Rio de Janeiro, Forense - Universitária, 1978.

BOSI, Alfredo. Dialética da Colonização. São Paulo, Companhia das Letras, 1992.

CARNEIRO DA CUNHA, Manuela. "Introdução a uma História Indígena”. In CARNEIRO DA CUNHA, Manuela (org.) História dos Índios no Brasil. São Paulo, Companhia das Letras, 1992, pp.9-24.

Cartas Avulsas (1550-1568). Belo Horizonte: Itatiaia; São Paulo: EDUSP, 1988.

CLENDINNEN, Inga. Ambivalent Conquests: Maya and Spaniard in Yucatan, 1517-1570. Cambridge, Cambridge University Press, 1996.

DORSEY, Peter A. "Going to School with Savages: Authorship and Authority among the Jesuits of New France". William and Mary Quarterly, 3a. Série, vol. LV, No.3, Julho 1998, pp. 399-420.

ÉVREUX, Yves d'. Voyage dans le Nord du Brésil fait durant les années 1613 et 1614 / Svitte de l'Histoire des choses plus memorables advenues en Maragnan, es années 1613 \& 1614. Introdução e notas de M. Ferdinand Denis. Lepzig e Paris, Librairie A. Franck, 1864.

FAUSTO, Carlos. "Fragmentos de História e Cultura Tupinambá: Da etnologia como instrumento crítico de conhecimento etno-histórico". In CARNEIRO DA CUNHA, Manuela (org.). História dos Índios no Brasil. São Paulo, Companhia das Letras, 1992, pp. 381-396.

FLEISCHMANN, Ulrich et al. "Os Tupinamba: Realidade e Ficção nos Relatos Quinhentistas". Revista Brasileira de História. Vol. 10, n² 21, São Paulo, Set. 1990 - Fev. 1991, pp.125-145.

GEERTZ, Clifford. The Interpretation of Cultures: Selected Essays. New York, 1973.

GIDDENS, Anthony. Central Problems in Social Theory: Action, Structure and Contradiction in Social Analysis. Berkeley, University of California Press, 1979.

The Constitution of Society. Berkeley, University of California Press, 1984.

GREENBLATT, Stephen (ed.). New World Encounters. Berkeley,
University of California Press, 1993.

Possessões Maravilhosas: O Deslumbramento do Novo Mundo. São Paulo, EDUSP, 1996.

HAGEDORN, Nancy L. "'A great deal depends upon the Interpreters': Anglo-Iroquois Relations and Imperial Diplomacy in the Colonial Northeast, 1664-1774". Atlantic History Seminar Papers, Cambridge, Mass., Harvard University, 1997, Working Paper No. 97-23.

HEMMING, John. Red Gold: The Conquest of the Brazilian Indians. Londres, Macmillan, 1978.

HUNTER, Charles E.. "The Delaware Nativist Revival of the MidEighteenth Century”. Ethnohistory 18, 1971, pp.39-49.

JAENEN, Cornelius J. "Amerindian Views of French Culture in the Seventeenth Century". Canadian Historical Review LV, 1974, pp.261-291.

Friend and Foe: Aspects of French-American Cultural Contact in the Sixteenth and Seventeenth Centuries. Ontario, Mc Clelland and Stewart Limited, 1976.

KUPPERMAN, Karen Ordahl. Settling with the Indians: The Meeting of English and Indian Cultures in America, 15801640. Totowa, New Jersey, Rowman and Littlefield, 1980.

LEITE, Serafim (org.). Monumenta brasiliae. Roma, Archivum Romanum Societatis Iesu, 1956-68, 5 vols..

LOCKART, James. "Sightings: Initial Nahua reactions to Spanish culture". In SCHWARTZ, Stuart B. (ed.). Implicit Understandings: Observing, Reporting, and Reflecting on the Encounters Between Europeans and Other Peoples in the Early Modern Era. Cambridge, Cambridge University Press, 1994, pp. 218-248.

LOYOLA, Inácio de. Monumenta Ignatiana... Sancti Ignatii de Loyola Societatis Jesu fundatoris, epistolae et instructiones. Madrid, 1903-1911, 12 vols.

MAESTRI, Mário. Os Senhores do Litoral: Conquista Portuguesa e Agonia Tupinambá no Litoral Brasileiro. Porto Alegre, Editora da Universidade/ UFRGS, 1994.

MELLO E SOUZA, Laura de. O Diabo e a Terra de Santa Cruz: Feitiçaria e Religiosidade Popular no Brasil Colonial. São Paulo, Companhia das Letras, 1986.

Inferno Atlântico: Demonologia e Colonização, Séculos XVI - XVIII. São Paulo, Companhia das Letras, 1993.

MÉTRAUX, Alfred. A religião dos tupinambás e suas relações com a das demais tribos tupi-guaranis. São Paulo, Editora Nacional; EDUSP, 1979.

NÓBREGA, Manuel da. Cartas do Brasil (1549-1560). Rio de Janeiro, Officina Industrial Graphica, 1931 (Cartas jesuíticas I). 
Dialogo sobre a conversão do gentio. Introdução e notas de Serafim Leite, Lisboa, Comissão do IV Centenário, 1954.

. Cartas do Brasil e Mais Escritos (Opera Omnia). Com Introdução e Notas Históricas e Críticas de Serafim Leite. Coimbra, Editora da Universidade de Coimbra, 1955.

RAMINELLI, Ronald. Imagens da Colonização: A Representação do Indio de Caminha a Vieira. Rio de Janeiro: Jorge Zahar; São Paulo: EDUSP, 1996.

RONDA, James P. “'We Are Well As We Are': An Indian Critique of Seventeenth-Century Christian Missions". William and Mary Quarterly 34, 1977, pp.66-82.

SAHLINS, Marshall. Historical Metaphors and Mythical Realities: Structure in the Early History of the Sandwich Islands Kingdom. ASAO Special Publication 1, Ann Arbor, Michigan, 1981.

Ilhas de História. Rio de Janeiro, Jorge Zahar Editor, 1990 .

SALISBURY, Neil. "Red Puritans: The 'Praying Indians' of Massachusetts Bay and John Eliot”. William and Mary Quarterly 31, 1974, pp.27-54.

SALVADOR, Frei Vicente. Historia do Brasil (1627). Ed. Capistrano de Abreu e Rodolpho Garcia. São Paulo, Melhoramentos, 1931.
SCHWARTZ, Stuart B. Sugar Plantations in the Formation of Brazilian Society, Bahia 1550-1835. Cambridge, Cambridge University Press, 1985.

(ed.). Implicit Understandings: Observing, Reporting, and Reflecting on the Encounters Between Europeans and Other Peoples in the Early Modern Era. Cambridge, Cambridge University Press, 1994.

SOARES DE SOUSA, Gabriel. Tratado Descriptivo do Brasil em 1587. Ed. Francisco Adolfo Varnhagen, São Paulo, Nacional, 1938.

VAINFAS, Ronaldo. A Heresia dos Indios: Catolicismo e rebeldia no Brasil colonial. São Paulo, Companhia das Letras, 1995.

VASCONCELLOS, Simão de. Chronica da Companhia de Jesu do Estado do Brasil, e do que obrarão seus filhos n'esta parte do Novo Mundo. Lisboa, Off. Henrique Valente de Oliveira, 1663.

WAGNER, Roy. The Invention of Culture. New Jersey, PrenticeHall, 1975.

WALLACE, Anthony F. C.. "Revitalization Movements: Some Theoretical Considerations for Their Comparative Study". American Anthropologist LVIII, 1956, pp.264-281.

WHITE, Richard. The Middle Ground: Indians, Empires and Republics in the Great Lakes Region, 1650-1815. Cambridge, Cambridge University Press, 1991. 